\title{
Efecto de polifenoles de la dieta mediterránea sobre la proliferación y mediadores de la invasividad "in vitro" de la línea de cáncer vesical murino MB-49
}

\author{
J.M. García Mediero, A. Ferruelo Alonso, A. Páez Borda, M. Luján Galán, J. Angulo Cuesta, \\ V. Chiva Robles, A. Berenguer Sánchez
}

Servicio de Urología. Hospital Universitario de Getafe. Madrid.

Actas Urol Esp 2005; 29 (8): 743-749

\section{RESUMEN}

EFECTO DE POLIFENOLES DE LA DIETA MEDITERRÁNEA SOBRE LA PROLIFERACIÓN Y MEDIADORES DE LA INVASIVIDAD “IN VITRO” DE LA LÍNEA DE CÁNCER VESICAL MURINO MB-49

Objetivo: Evaluar el efecto de diferentes polifenoles sobre la proliferación y algunos mediadores implicados en el proceso de invasividad en la línea celular MB-49.

Material y Métodos: Cultivos de células de cáncer vesical murino MB-49 se suplementaron con resveratrol, rutina, morina, quercetina y ácidos tánico y gálico, a diferentes concentraciones y se determinó la proliferación celular a las 24, 48 y 72 horas. Por otra parte, se cuantificó la expresión del activador del plasminógeno tipo Urokinasa (u-PA) y de su receptor (u-PAR), así como de la metaloproteinasas 9 (MMP-9) mediante PCR en tiempo real tras $24 \mathrm{~h}$ de tratamiento con cada nutriente. Además, se valoró en el medio de cultivo, también tras 24 horas de incubación con los diferentes nutrientes, los niveles de MMP-9.

Resultados: Todos los polifenoles estudiados consiguieron inhibir la proliferación de las células MB-49 de manera significativa, variando en los tiempos y dosis empleados. La expresión de del activador del plasminógeno tipo Urokinasa (u-PA) y de su receptor de alta afinidad (u-PAR) no se vieron modificados tras el tratamiento, siendo en algún caso ligeramente aumentada su expresión. Sin embargo, si se inhibió de manera significativa tanto la expresión como los niveles en el medio de cultivo de la MMP-9.

Conclusiones: Los polifenoles de nuestra dieta habitual ejercen un efecto inhibidor sobre la proliferación y los mediadores de la invasividad tumoral vesical en células MB-49.

Palabras Clave: Invasividad. Polifenoles. upA. uPAR. MMP9. Cáncer vesical. MB49

\section{ABSTRACT}

(EFFECT OF POLYPHENOLS IN THE MEDITERRANEAN DIET ON PROLIFERATION AND MEDIATORS OF IN VITRO INVASIVENESS OF THE MB-49 MURINE BLADDER CANCER CELL LINE)

Objective: To evaluate the effect of different polyphenols on the proliferation and invasive capacity of MB-49 murine bladder tumor cell lines and to identify the mediators involved in this process.

Materials and Methods: MB-49 murine bladder cancer cells were cultured in media supplemented with resveratrol, rutin, morin, quercetin, gallic acid and tannic acid (all of them are polyphenols usually present in Mediterranean diet) for periods of 24,48 and 72 hours to quantify the expression of urokinase-type plasminogen activator (UPA) and its receptor (uPAR) in the culture medium, as well as of metalloproteinase-9 (MMP-9) and cell proliferation.

Results: All the polyphenols studied significantly inhibited proliferation of MB-49 cells, varying according to the time periods and doses used. The cells in the media supplemented with the nutrients to study did not show inhibition of mRNA expression of urokinase-type plasminogen activator (uPA) or its high affinity receptor (uPAR). It was even slightly increased in certain cases. However, mRNA expression of metalloproteinase- 9 was strongly inhibited.

Conclusions: The polyphenols present in our usual diet exert an effect on the proliferation and mediators of bladder tumor invasiveness in MB-49 cells.

Keywords: Invasiveness. Polyphenols. upA. uPAR. MMP9. Bladder cancer. MB49.

Financiado parcialmente por la Fundación para la Investigación de Urología de la Asociación Española de Urología. 
$\mathrm{E}$ cáncer de vejiga es el cuarto cáncer en frecuencia entre los hombres y el octavo en frecuencia entre las mujeres, representando el 10\% y el $4 \%$ de todos los cánceres, respectivamente. Aunque el 65-80\% de los tumores vesicales debutan como superficiales con un comportamiento relativamente benigno, las recurrencias a los 5 años alcanzan el 65\%, mientras que cerca del 15\% de los tumores progresan a enfermedad musculoinfiltrante. Lamentablemente, no es posible identificar con seguridad aquellos pacientes expuestos a la progresión. Una vez que se ha producido la progresión, el patrón oro del tratamiento es la cirugía radical, aunque casi el 50\% de los pacientes con mal pronóstico (pT4, pN+, márgenes positivos, etc.) tratados con cistectomía radical aislada morirán por enfermedad metastásica ${ }^{1}$. De esta manera, la prevención de la progresión podría representar un paso adelante en el tratamiento del cáncer de vejiga. En este sentido, la infiltración tumoral se produce como consecuencia de la acción de enzimas que degradan las proteínas de la membrana basal y la matriz extracelular ${ }^{2}$. Entre estas, la enzima activadora del plasminógeno-tipo urokinasa (uPA) y su receptor de alta afinidad (UPAR), son críticos en la progresión y capacidad metastásica del tumor y su nivel de expresión se correlaciona con un mal pronóstico en diferentes tipos de cánceres , como el de próstata ${ }^{3}$, mama $^{4}$, colon $^{5}$, ovario ${ }^{6}$, gástrico ${ }^{7}$, cerebro $^{8}$, y pulmón ${ }^{9}$. La urokinasa (uPA) y su principal producto, la plasmina pertenecen a una serie de proteasas ${ }^{10-12}$ que activan la cascada de las metaloproteasas (MMP), las cuales están implicadas en procesos fisiológicos normales (migración celular, angiogénesis, etc.) y procesos patológicos (crecimiento y migración tumoral, artrítis, etc.). Así, controlan procesos como la motilidad celular, remodelación tisular y la activación de diferentes factores angiogénicos (VEGF, TGF $\beta$ ). La mayoría de estas proteasas (ej. uPA) se encuentran localizadas en el propio tumor a través de receptores que se expresan de manera muy elevada en la superficie de células endoteliales activadas y tumorales, y se ha demostrado que la expresión de uPA es un factor pronóstico independiente de recurrencias y progresión en el cáncer vesical ${ }^{18}$. Es decir, la acción de estas enzimas permite que las células tumorales escapen al control local y adquieran capacidad metastásica ${ }^{13}$. Un tratamiento que minimizara la actividad de esas proteínas dificultaria la progresión hacia este estado más agresivo.

Los flavonoides son metabolitos secundarios de las plantas con propiedades antioxidantes presentes en las frutas, vegetales, y bebidas como el té, el vino (sobre todo el tinto) y los zumos de frutas $^{14-16}$. La ingesta diaria de flavonoides se encuentra en el rango 10-100mg. El vino tinto y el mosto son particularmente ricos en flavonoides en comparación con el vino blanco y la cerveza. También existen evidencias sobre el efecto anticancerígeno de los taninos y de la quercetina, ambos presentes en el vino ${ }^{17}$.

Según lo comentado previamente, queremos investigar el efecto de diferentes agentes de la dieta mediterránea, como son los polifenoles investigados, sobre la proliferación e invasividad tumoral.

\section{MATERIAL Y MÉTODOS}

Cultivo celular y tratamientos. Se utilizaron células tumorales de la línea de cáncer vesical murino MB-49 (obtenida mediante inducción con 7,12-dimetilbenzoantraceno en ratones macho de la cepa C57BL/Icrf-a') (Fig. 1). Las células fueron mantenidas en medio de cultivo Dulbecco's modified eagle medium (DMEM, Gibco BRL, Barcelona Spain) con $10 \%$ de suero fetal de ternera (FCS) y suplementadas con L-glutamina 2 mM (Gibco BRL, Barcelona Spain), penicilina 100 $\mathrm{U} / \mathrm{ml}$ y estreptomicina $100 \mathrm{ug} / \mathrm{ml}$ (Gibco BRL, Barcelona Spain) e incubadas en estufa a $37^{\circ} \mathrm{C}$ y con una atmósfera de $\mathrm{CO}_{2}$ al $5 \%$.

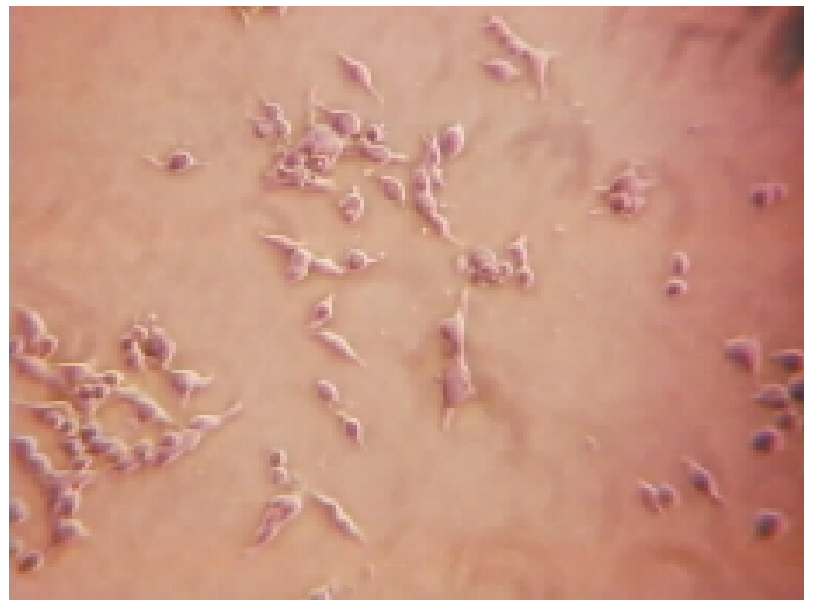

FIGURA 1. Células tumorales vesicales murinas de la linea MB-49. 
Las células fueron tratadas con ácido gálico, ácido tánico, quercetina, rutina, morina y resvera trol a las concentraciones y tiempos indicados. Todos los polifenoles utilizados se obtuvieron de Sigma-Aldrich (St. Louis, MO, USA) y se disolvieron en methanol (los cuatro primeros) o DMSO (resto). Se prepararon soluciones stock que se almacenaron a $-20^{\circ} \mathrm{C}$. Las concentraciones utilizadas en los diferentes ensayos se alcanzaron diluyendo las soluciones stock con medio DMEM. Las células control recibieron DMSO o etanol a una concentración final del 0,1\%.

Ensayos de proliferación. Las células se subcultivaron en placas de 96 pocillos a una densidad de $1,5 \times 10^{3}$ células por pocillo en $100 \mu \mathrm{lde}$ medio. Tras una preincubación de $12 \mathrm{~h}$, se aportaron los diferentes polifenoles a las diferentes dosis y se determinó la proliferación celular a las 24,48 y $72 \mathrm{~h}$ posteriores al tratamiento mediante la técnica de incorporación de la bromodeoxiuridina (BrdU) al ADN de células proliferantes, según recomendaciones del fabricante (Cell Proliferation ELISA BrdU, Roche, USA). La BrdU se detecta mediante inmunoensayo por determinación de la absorbancia a $450 \mathrm{~nm}$ en un lector de placas (Bio-Tek Instruments, Winooski, USA). Los valores de absorbancia se correlacionan con la sintesis de $\mathrm{ADN}$ y con el número de células proliferantes. Los experimentos se realizaron por triplicado y los resultados se expresaron como unidades de absorbancia (AU).

Obtención de RNA. Se utilizó el kit Rneasy (Qiagen, Izasa, España) de acuerdo a las instrucciones del fabricante. La calidad del RNA se determinó por absorbancia a 260/280nm.

PCR en tiempo real. Se realizó una transcripción reversa con $1 \mu \mathrm{g}$ de RNA total para cada muestra utilizando cebadores al azar (random primers) y la enzima MMLV, según recomendaciones del fabricante (Sigma, St. Louis, MO, USA). La PCR en tiempo real se realizó en un termociclador iCycler (BioRad Laboratories, Hercules, CA, USA) con $25 \mathrm{ml}$ de una mezcla de reacción compuesta de 12,5 $\mu \mathrm{l}$ Universal PCR Master Mix (Applied Biosystems, The Netherlands), $1,25 \mathrm{ml}$ de una mezcla de primers de PCR no marcados (uPA, UPAR, MMP9 o 18S) y una sonda and Taqman MGB específica para cada una de las dianas a estudio (TaqMan Assay, Applied Biosystems, The Netherlands). La
PCR a tiempo real tiene el siguiente protocolo: 5 minutos a $95^{\circ} \mathrm{C}$ para activar la Taq Polimerasa, y 40 ciclos con $95^{\circ} \mathrm{C} 15$ segundos y $60^{\circ} \mathrm{C}$ un minuto. Como control endógeno se utilizó un gen ubicuo como el $18 \mathrm{~S}$ ribosomal. Para determinar la cantidad relativa de cada diana en cada muestra, los resultados se normalizaron por el valor obtenido para el $18 \mathrm{~S}$ y se utilizó el método CT compartivo $\left(\Delta \Delta \mathrm{C}_{\mathrm{T}}\right)$ que compara $\mathrm{CT}$ (ciclo umbral) entre tratamientos. Para poder utilizar este método se comprobó que las eficiencias de la amplificación para cada uno de los genes a estudio (MMP-9, UPA y UPAR) respecto al $18 \mathrm{~S}$ fueran aproximadamente equivalentes. Si esto es así, el valor absoluto de la pendiente que se genera al representar los $\Delta \mathrm{CT}$ (CT gen diana - CT gen de referencia) respecto al log (RNA total) utilizado para realizar la curva, tiene que ser $<0,1$. En todos los casos se consiguieron pendientes inferiores a 0,1 , lo que permitió utilizar el método CT comparativo.

ELISA MMP-9. Los niveles de MMP-9 en el sobrenadante se determinaron mediante un ensayo de ELISA (R\&D Systems) según recomendaciones del fabricante.

Análisis Estadístico. Para el tratamiento estadístico de todos los resultados (medias) se utilizó un ANOVA unifactorial. Se consideraron significativos valores de $\mathrm{p}<0,05 \mathrm{y}$ el software utilizado fue el SPSS 11.5.

\section{RESULTADOS}

\section{Proliferación celular}

Como aparece reflejado en la (Fig. 2) todos los polifenoles utilizados consiguieron inhibir de manera significativa la proliferación de las células MB49, aunque con diferentes potencias y tiempos. $\mathrm{El}$ efecto para todos los polifenoles fue dosis y tiempo dependiente. El ácido tánico fue el polifenol que tardó menos tiempo en ejercer su acción ya que a las 24 horas se apreció una reducción en la proliferación tanto a 5 como a $10 \mu \mathrm{M}$ con respecto al control. En contraste, el polifenol con efecto más tardío fue la rutina, ya que su efecto, con ambas concentraciones, no se hace patente hasta pasadas 72 horas. El ácido gálico consigue efectos a la dosis de $75 \mu \mathrm{M}$ desde las 24 horas. Sin embargo a las 48 y 72 horas disminuye significativamente la proliferación con respecto al control con ambas dosis (mayor cuanto más tiempo pasa). 


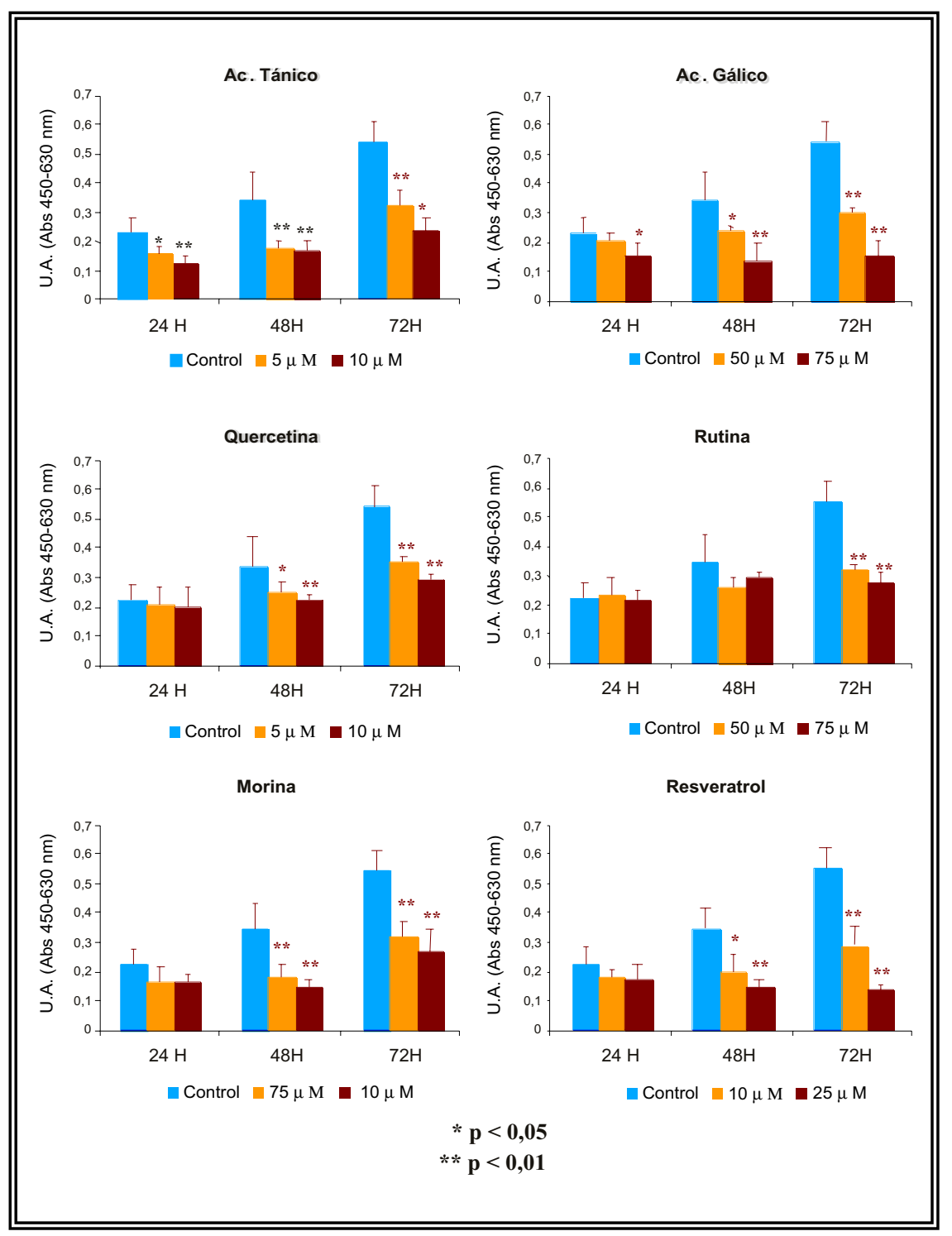

FIGURA 2. Proliferación celular de la línea celular MB-49 y su inhibición en medios ricos en los diferentes polifenoles estudiados.

De similares características es la curva de proliferación de la quercetina y el resveratrol, ya que ambos polifenoles empiezan a inhibir la proliferación a partir de las 48 horas, y a medida que aumenta la dosis (5 y $10 \mu \mathrm{M}$ para quercetina y 10 y $25 \mu \mathrm{M}$ para resveratrol) y el tiempo la inhibición de la proliferación es mayor.

La morina fue el polifenol que necesito una mayor concentración para conseguir disminuir la proliferación (75 y $100 \mu \mathrm{M})$, requiriendo además un mínimo de 48 horas para manifestar sus efectos, aunque una vez producidos fueron significativamente muy relevantes.
Expresión de uPA, uPAR y MMP9 Los resultados obtenidos por PCR en tiempo real se muestran como número de veces que se encuentra expresado o inhibido el gen diana en función del tratamiento y respecto a la situación control. Los resultados se analizaron mediante el método del Ct comparativo (Applied Biosystems) y se normalizaron con un control interno (18S). En la Tabla 1 y 2 se muestran los resultados de la enzima activadora del plasminógeno-tipo urokinasa ( $u P A)$ y su receptor ( $U P A R)$. Se aprecia que ninguno de los compuestos modifica de manera significativa la expresión de ninguno de los genes a estudio, excepto la quercetina que aumenta 2,8 y 2,6 veces la expresión de uPAy uPAR respectivamente.

Por último, en cuanto a la capacidad de alterar la expresión de la MMP-9 los resultados fueron los indicados en la Tabla 3. Todos los polifenoles fueron capaces de inhibir la expresión de la MMP9 de manera significativa. En particular la quercetina y la morina, fueron los compuestos más potentes de los estudiados, llegando a inhibirla en un factor de 6,35 y 7,21 respectivamente, respecto a la situación control (Fig.3).

\section{Niveles de MMP-9}

En la Figura 4 se observa que todos los nutrientes fueron capaces de disminuir la secreción de MMP-9 al medio de cultivo. La potencia de inhibición alcanza por cada uno de los nutrientes se muestra en porcentaje con respecto al control (100\%). Así, el polifenol que alcanzó el efecto más potente fue la morina (40\% inhibición) y el más débil fue el ácido tánico (10\% inhibición). Se puede observar la existencia de una clara relación entre la inhibición en la expresión y la secreción de la MMP9 para cada uno de los polifenoles. 
Tabla 1

Efecto de los polifenoles sobre la expresión del mARN del activador del plasminógeno uPA. Los valores se expresan como número de veces aumentada la expresión con respecto a la situación control.

\begin{tabular}{lcc}
\hline No veces & Estimulación UPAR & Versus control \\
\hline Control & 1,00 & $(0,90-1,11)$ \\
Tánico & 1,25 & $(1,06-1,47)$ \\
Gálico & 1,08 & $(0,90-1,31)$ \\
Quercetina & 0,95 & $(0,85-1,07)$ \\
Rutina & 2,80 & $(2,57-3,03)$ \\
Morina & 1,05 & $(0,92-1,20)$ \\
Resveratrol & 1,26 & $(0,89-1,18)$ \\
\hline
\end{tabular}

Tabla 2

Efecto de los polifenoles sobre la expresión del mARN del receptor del activador del plasminógeno Upa. Los valores se expresan como número de veces aumentada la expresión con respecto a la situación control.

\begin{tabular}{lcc}
\hline No veces & Estimulación UPA & Versus control \\
\hline Control & 1,00 & $(0,88-1,08)$ \\
Tánico & 1,50 & $(1,08-1,44)$ \\
Gálico & 1,11 & $(0,94-1,26)$ \\
Quercetina & 1,05 & $(0,85-1,07)$ \\
Rutina & 2,61 & $(2,54-3,00)$ \\
Morina & 1,10 & $(0,93-1,18)$ \\
Resveratrol & 1,66 & $(0,91-1,15)$ \\
\hline
\end{tabular}

\section{Tabla 3}

Efecto de los polifenoles sobre la expresión del mARN de la MMP9. Los valores se expresan como número de veces inhibida la expresión con respecto a la situación control.

\begin{tabular}{lcc}
\hline No veces & Inhibición MMP & Versus control \\
\hline Control & 1,00 & $(0,83-1,21)$ \\
Tánico & 2,67 & $(1,80-3,96)$ \\
Gálico & 4,00 & $(2,94-5,43)$ \\
Quercetina & 6,35 & $(5,65-7,13)$ \\
Rutina & 4,44 & $(3,69-5,33)$ \\
Morina & 7,21 & $(5,61-9,26)$ \\
Resveratrol & 3,61 & $(2,62-4,95)$ \\
\hline
\end{tabular}

\section{DISCUSION}

En líneas generales, la dieta mediterránea es considerada como protectora frente al cáncer, quizá como consecuencia de su bajo contenido en grasas animales y carnes y su elevado contenido en frutas frescas, pasta y vino. Por ello, nos hemos centrado en varios polifenoles que se encuentran en altas concentraciones en distintos alimentos de la dieta mediterránea.

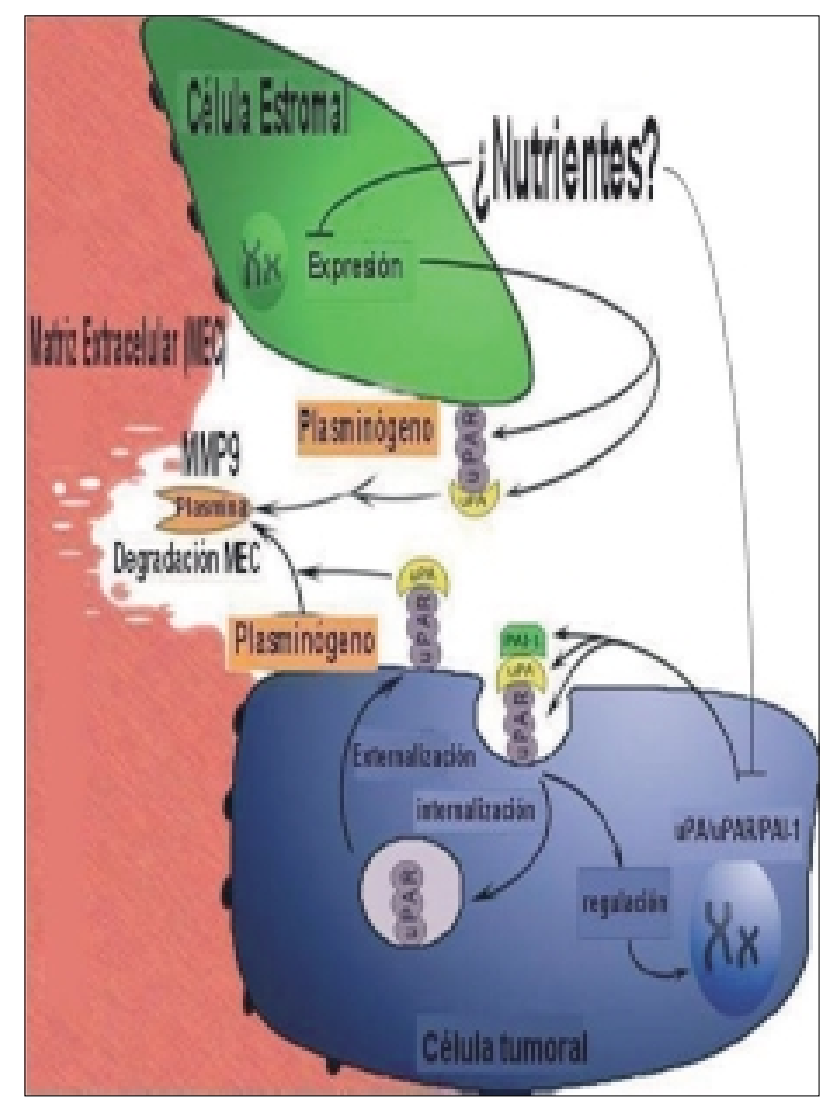

FIGURA 3. Fisiologia del sistema uPA-uPAR-MMP. La acción conjunta del UPA unida a su receptor UPAR y la acción de las metaloproteinasas MMP es indispensable para la degradación de la lámina propia y la matriz extracelular, elemento clave en la invasividad tumoral.

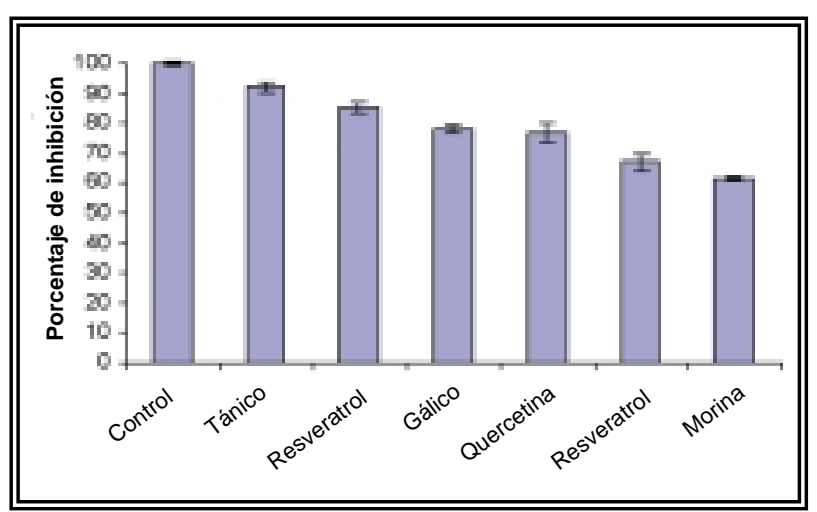

FIGURA 4. Efecto de los polifenoles sobre los niveles de MMP-9 en sobrenadante. Los valores se expresan en porcentaje respecto al control (100\%).

Se han publicado numerosos estudios demostrando asociaciones entre la ingesta de alimentos ricos en polifenoles y la prevención de diferentes enfermedades, tales como diferentes tipos de tumores, accidentes cerebrovasculares y enferme- 
dades cardiovasculares, estos últimos especialmente relacionados con la ingesta de te y vino respectivamente $^{19}$.

Aunque se han identificado cerca de 4000 polifenoles en diferentes plantas, sólo una relativa cantidad de ellas se encuentran en cantidades significativas en la dieta humana ${ }^{19}$. $\mathrm{El}$ grupo de los flavonoides ha sido el más estudiado hasta la fecha siendo los polifenoles más frecuentes en nuestra dieta ${ }^{20,21}$

En los últimos años se ha puesto especial énfasis en estudiar estos compuestos al demostrarse el papel de algunas plantas y frutas en la prevención de diferentes tipos de tumores ${ }^{22}$. Se han postulados diferentes mecanismos de acción mediante los cuales los diferentes polifenoles podrían ejercer una acción preventiva tumoral ${ }^{23}$. También ha sido demostrada su capacidad para inhibir, "in vitro", las metaloproteinasas MMP2 y MMP9, enzimas clave en la el proceso de invasividad de una célula tumoral ${ }^{20}$. La biodisponibilidad de estos compuestos es determinante a la hora de ejercer su acción y esta condicionada a múltiples factores como el microambiente bacteriano del colon del consumidor, mecanismos de absorción intestinal, etc. ${ }^{23}$.

En nuestro trabajo hemos puesto de manifiesto la capacidad de varios polifenoles, de los más frecuentes en nuestra dieta, para inhibir la proliferación "in vitro" de la línea celular tumoral murina, MB-49. Polifenoles presentes en la dieta mediterránea, sobre todo en el vino tinto, también inhiben la proliferación en otros tumores urológicos como el de próstata. Romero y colaboradores en este mismo centro demostraron que estos mismos polifenoles fueron capaces de inhibir in vitro la proliferación e inducir la apoptosis en células humanas de cáncer de próstata LnCap ${ }^{26,29}$.

También hemos objetivado que se altera la expresión del mARN de los mediadores de la invasividad estudiados en un medio suplementado con estos nutrientes,. El hecho de que en presencia de los nutrientes aumente levemente la expresión del mARN de la enzima activadora del plasminógeno-tipo urokinasa (uPA), pero que prácticamente no se altere su receptor de alta afinidad (UPAR) probablemente no tenga efecto biológico. Hay evidencias de que es el complejo uPAuPAR y no el uPA libre el que inicia la cascada de procesos que culmina con la metástasis ${ }^{27}$.
Kim y colaboradores van más allá y demostraron que es necesaria la plena cooperación entre el sistema uPA-uPAR y las metaloproteinasas (ej.: MMP 9) para que se inicie el proceso de invasivi$\mathrm{dad}^{28}$.

Por otra parte, múltiples trabajos han puesto de manifiesto el papel determinante del sistema UPA - UPAR en la progresión y capacidad metastásica del tumor. Hasui y cols., en un estudio sobre uPA y tumores vesicales superficiales, comunicaron que la expresión de uPA era un factor pronóstico independiente de recurrencias y progresión en el cáncer vesical ${ }^{18}$. Hudson estudió la influencia de uPA y uPAR sobre la invasividad en 4 diferentes líneas de tumor vesical y apreció que para que se produjera la invasión in vitro, las células tenian que producir uPA y expresar el uPAR de manera simultánea. Es decir, para que la célula tumoral vesical adquiera capacidad invasiva tiene que estar aumentadas tanto la enzima como su receptor, ambos son necesarios para que se produzca la invasión ${ }^{24}$.

Todos los nutrientes estudiados consiguieron inhibir la expresión del mRNA de la metaloproteinasa 9 (MMP9). Esta acción fue más pronunciada en el caso de la morina y la quercetina. Sier y colaboradores estudiaron los niveles de MMP 9 en orina de pacientes con tumores vesicales y los compararon con los niveles de sujetos sanos. Comprobaron que los niveles de MMP9 en pacientes con tumores fueron significativamente mayores que en los sujetos sanos. Además los pacientes con tumores musculoinfiltrantes sobreexpresaban de una manera significativa esta enzima ${ }^{25}$.

Este dato junto con que todos estos compuestos consiguen inhibir in vitro, según tiempo y dosis, la proliferación de las células tumorales vesicales hacen necesario seguir investigando para estudiar los mecanismos a través de los cuales estos polifenoles ejercen sus efectos sobre proliferación e invasividad.

\section{CONCLUSIONES}

Los polifenoles estudiados (resveratrol, rutina, morina, quercetina, y ácidos tánico y gálico) consiguieron inhibir la proliferación, a diferentes tiempos y dosis, de la línea celular tumoral vesical murina MB-49. También consiguieron inhibir 
la expresión de mediadores críticos en el desarrollo de la capacidad invasiva de un tumor como la metaloproteinasa 9. Sin embargo, no ejerció ningún efecto sobre la enzima activadora del plasminógeno-tipo urokinasa y su receptor de alta afinidad. Estos resultados hacen necesario seguir investigando con cámaras de invasividad en lineas celulares humanas con el fin de diseñar una eventual estrategia de potencial prevención de la invasividad tumoral basado en agentes de nuestra dieta habitual.

\section{REFERENCIAS}

1. Sana Al-Sukhun, Maha Hussain. Molecular biology of Transicional cell carcinoma. Critical Reviews in oncology/hematology 2003 1-13, art. In press.

2. Sambrook J, Fritsch EF, Maniatis T. Molecular Cloning: A laboratory Manual, $2^{\text {nd }}$ ed. Cold Spring Laboratory Press, Cold Spring Harbor, New York.

3. Miyake H, Hara I, Yamanaka K, Arakawa S, Kamidono S. Elevation of urokinase-type plasminogen activator and its receptor densities as new predictors of disease progression and prognosis $1 \mathrm{n}$ men with prostate cancer. Int $\mathrm{J}$ Oncol 1999; 14:535-541.

4. Costantini V, Sidoni A, Deveglia R, Cazzato OA, Bellezza G, Ferri I, et al. Combined over expression of urokinase, urokinase receptor, and plasminogen activator inhibitor-1 is associated with breast cancer progression: an immunohistochemical comparison of normal, benign, and malig nant breast tissues.Cancer1996;77:1079-1088.

5. Skelly MM, Troy A, Duffy MJ, Mulcahy HE, Duggan C, Connell TG, et a. Urokinase-type plasminogen activator in colorectal cancer: relationship with clinicopathological features and patient outcome.Clin Cancer Res 1997;3:18371840.

6. Van der Burg ME, Henzen-Logmans SC, Berns EM, van Putten WL, Klijn JG, Foekens JA. Expression of urokinasetype plasminogen activator (uPA) and its inhibitor PAI- 1 in benign, borderline, malignant primary and metastatic ovarian tumors. Int J Cancer 1996;69:475-479.

7. Ito H, Yonemura Y, Fujita H, Tsuchihara K, Kawamura T, Nojima N, et al. Prognostic relevance of urokinase-type plasminogen activator (uPA) and plasminogen activator inhibitors PAI-1 and PAI-2 in gastric cancer. Virchows Arch 1996;427:487-496.

8. Zhang $X$, Fei $Z$, Bu X, Zhen $H$, Zhang $Z$, Gu J, et al. Expression and significance of urokinase type plasminogen activator gene in human brain gliomas. J Surg Oncol 2000;74:90-94.

9. Takanami I, Takeuchi K, Karuke M: Expression of ETS-1 is correlated with urokinase-type plasminogen activator and poor prognosis in pulmonary adenocarcinoma. Tumour Biol 2001;22:205-210.

10. De Vries TJ, Guax PH, Denijn M, Verrijp KN, Verheijen JH, Verspaget HW, et al. Plasminogen activators, their inhibitors, and urokinase receptor emerge in late stages of melanocytic tumor progression. Am J Pathol 1994;144:7081 .

11. He CS, Wilhelm SM, Pentland AP, Marmer BL, Grant GA, Eisen AZ, et al. Tissue cooperation in a proteolytic cascade activating human interstitial collagenase. Proc Natl Acad Sci U S A 1989;86:2632-2636.
12. Mazzieri R, Masiero L, Zanetta L, Monea S, Onisto M, Garbisa S, et al. Control of type IV collagenase activity by components of the urokinase-plasmin system: a regulatory mechanism with cell-bound reactants. Embo J 1997; 16: 2319-2332.

13. Hudson MA, McReynolds LM. Urokinase and the urokinase receptor: association with in vitro invasiveness of human bladder cancer cell lines. J Natl Cancer Inst 1997 May 21;89(10):709.

14. E Rice-Evans CA, Miller NJ, Paganga G. Structure- antioxidant activity relationships of flavonoids and phenolic acids. Free Radic Biol Med 1996;20:933-956.

15. Thompson IM, Coltman CA, Crowly J. Chemoprevention of prostate cancer: The Prostate Cancer Prevention Trial. Prostate 1997;33(3):217-221.

16. Miksicek RJ. Commonly occurring plant flavonoids have estrogenic activity. Molec. Pharmacol 1993;44:37-43.

17. Lairon D, Amiot MJ. Flavonoids in food and natural antioxidants in wine. Curr Opin Lipidol 1999;10:23-28.

18. Hasui Y, Maratsaka K, Asada Y, Osada Y. Prognostic value of urokinase-type plasminogen activator in patients with superficial bladder cancer. Urology 1996;47:34.

19. Scalbert A, Williamson G. Dietary intake and bioavailability of Polyphenols. J Nutr 2000;130:2073S-2085S.

20. Sartor L, Pezzato E, Dell'Aica I, et al. Inhibition of matrizproteases by polyphenols: Chemical insights for antiinflammatory and anti-invasion drug design. Biochemical Pharmacology 2002;64:229-237.

21. Harbone JB. General procedures and mesurement of total phenolics. En P.M. Dey \& J.B. Harborne Eds, Methods in plant Biochemistry, Vol 1 pp1-28, London. Academic Press.

22. Block G, Patterson B, Subar A. Fruit, vegetables and cancer prevention: a review of the epidemiological evidence. Nutr Cancer 1992;18:1-29.

23. Birt D, Hendrich S, Wang W. Dietary agents in cancer prevention: flavonoids and isoflavonoids. Pharmacology \& Therapeutics 2001;90:157-177.

24. Hudson MA, McReynold LM. Urokinase (u-PA) and the uPA receptor. Modulation of in vitro invasiveness of human bladder cancer cell lines. Advances in Experimental Medicine \& Biology. 1999;462:399-412.

25. Sier CF, Casetta G, Verheijen JH, Tizzani A, Agape V, Kos $J$, et al. Enhanced urinary gelatinase activities (matrix metalloproteinases 2 and 9) are associated with earlystage bladder carcinoma: a comparison with clinically used tumor markers" Clinical Cancer Research. 2000 Jun; 6(6):2333-2340.

26. Romero Cagigal A, Ferruelo Alonso A, Berenguer Sánchez. Dieta y Cáncer de Próstata. Actas Urol Esp 2003;27(6): 399-409.

27. Blasi F. UPA, UPAR, PAI-1: key intersection of proteolytic, adhesive and chemotactic highways?. Immunol Today 1997; 18:415-417.

28. Kim J, Yu W, Kovalski K, Ossowski L. Requirement for specific proteases in cancer cell intravasation as revealed by a novel semiquantitative PCR-based assay. Cell 1998;7:353362.

29. Romero I, Páez A, Ferreruelo A, Luján M, Berenguer A. Polyphenols in red wine inhibit the proliferation and induce apoptosis of LNCaP cells. BJU International 2002;89 (9):950-954.

Dr. J.M. García Mediero

Jorge Juan 84, 6-C - 28009 Madrid

e-mail: garciamediero@hotmail.com

(Trabajo recibido el 28 diciembre 2004) 